This item was submitted to Loughborough's Research Repository by the author.

Items in Figshare are protected by copyright, with all rights reserved, unless otherwise indicated.

\title{
Lightweight deflectometers for quality assurance in road construction
}

PLEASE CITE THE PUBLISHED VERSION

PUBLISHER

(c) CRC Press (Taylor \& Francis Group)

VERSION

AM (Accepted Manuscript)

LICENCE

CC BY-NC-ND 4.0

REPOSITORY RECORD

Fleming, Paul R., Matthew W. Frost, and John Peter Lambert. 2019. "Lightweight Deflectometers for Quality Assurance in Road Construction”. figshare. https://hdl.handle.net/2134/5086. 
This item was submitted to Loughborough's Institutional Repository (https://dspace.lboro.ac.uk/) by the author and is made available under the following Creative Commons Licence conditions.

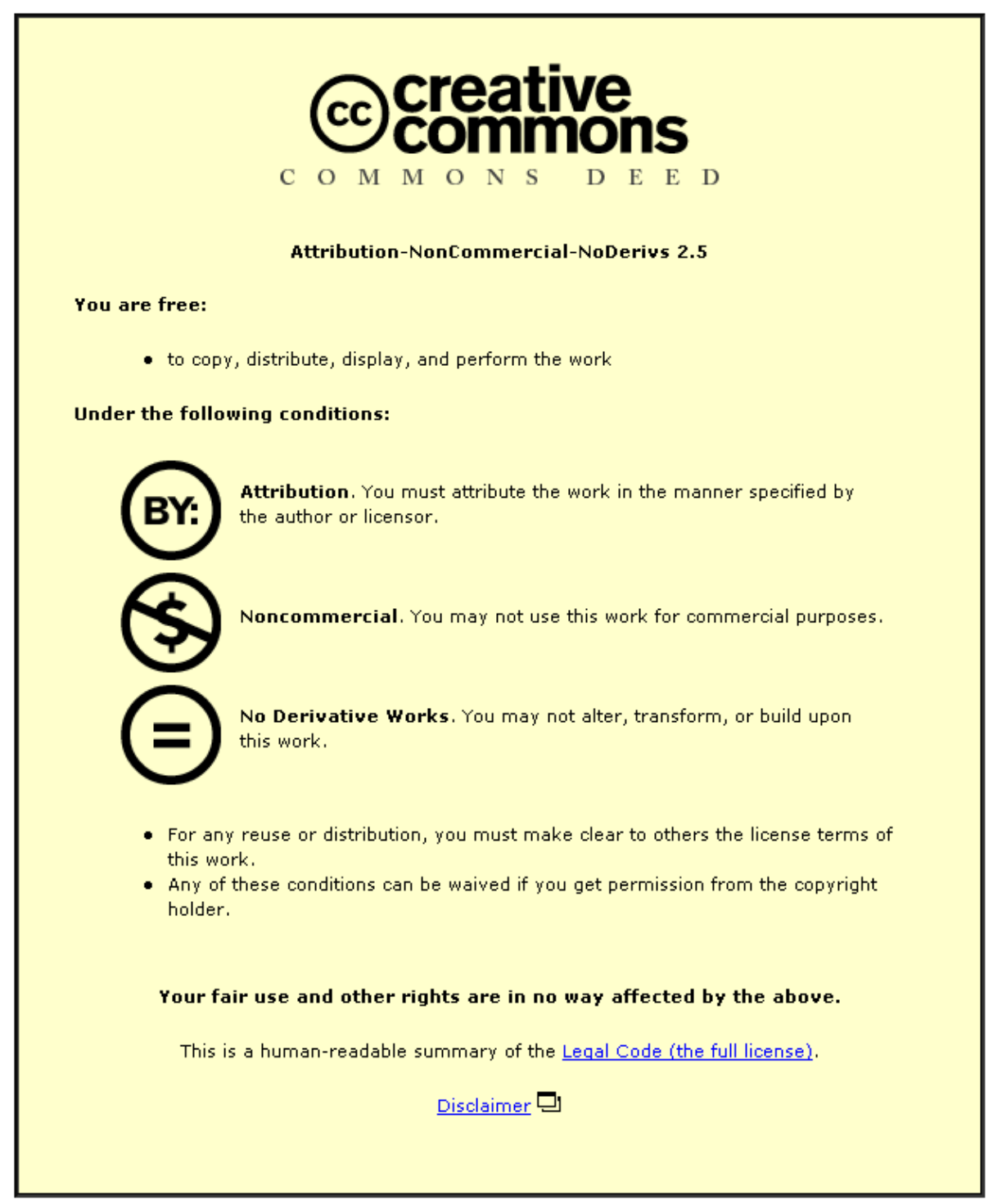

For the full text of this licence, please go to: http://creativecommons.org/licenses/by-nc-nd/2.5/ 


\title{
Lightweight Deflectometers for Quality Assurance in Road Construction
}

\author{
P.R Fleming \& M.W. Frost \\ Loughborough University, England, UK
}

J.P. Lambert

Scott Wilson, England, UK

\begin{abstract}
The use of Lightweight Deflectometers (termed LWDs in Europe, and occasionally PFWDs in the USA) for construction quality control or material investigation for road construction has increased worldwide. In the UK the change in pavement foundation design to a 'performance based approach' has brought about the use of Lightweight Deflectometers for field assessment of stiffness modulus. This paper reviews the LWD as a field evaluation tool. It discusses in some detail the test variables that can influence and affect the field data quality, and presents brief summaries of recent fieldwork where an LWD has been used as a quality control tool. The paper concludes both on the LWD usefulness and also its limitations for a variety of earthwork and road assessment scenarios, and describes a field test protocol for its use on a variety of materials. The findings demonstrate the flexibility of the LWD but also show that its determination of 'stiffness modulus' may differ from that of the conventional Falling Weight Deflectometer (FWD) to a varying extent. The paper provides a useful reference document for LWD users, consultants, material specifiers, contractors and clients.
\end{abstract}

\section{INTRODUCTION}

\subsection{Paper aim}

This paper reviews the use of Lightweight Deflectometers (LWD). In general it appears that the term PFWD can mean any portable device for measuring a stiffness of materials insitu, and the term LWD refers to the specific type of PFWD commonly used in Europe, manufactured by Grontmij-Carl Bro in Denmark or Dynatest of Sweden. To further confuse matters the term 'Dynamic Plate Test' has also been used in Europe to distinguish it from the traditional Static Plate bearing test. The LWD is increasingly used for investigations of road construction materials and quality control. A background to the LWD development, a review of recent case studies, correlation with the Falling Weight Deflectometer (FWD), and some specific laboratory investigations are presented and discussed. A 'best practice' guide is also briefly presented and discussed. This paper is intended for reference by LWD users, consultants, material specifiers, contractors and clients.

\subsection{Review of portable field stiffness measuring devices}

Many questions have arisen about the use and suitability of PFWDs, specifically when they are used as part of construction control within an end product or performance specification. The focus of much of the work in the UK has been on demonstrating the usefulness and reliability of the LWD through field trials. Little work has been carried out on detailed assessment of the influence of the test device variables on the potential outcomes of the measurements. Such variability assessments have mainly been performed on natural materials and these are intrinsically difficult to use to study repeatability and accuracy. 
The LWD has been available in its current form for several years, and earlier somewhat similar devices existed for measuring stiffness insitu included the prototype TRL Foundation Tester (TFT) (Rogers et al, 1995), the Natural Vibrations Method (NVM) (Fleming and Rogers, 1995), Leichtes Fallgerät from Zorn (known as the 'German Dynamic Plate' or GDP) (Fleming et al, 2002), the Soil Stiffness Gauge (also known as the SSG) (Fleming et al, 2002), the Loadman from Finland, the ODIN apparatus (Fleming and Rogers 1995) the Clegg Hammer (Fleming and Rogers 1995). All these devices have been described in more detail elsewhere, and can be categorized by the load pulse rate and intensity of maximum load (or contact pressure) (Fleming and Rogers, 1995). To summarize, the ODIN (a research prototype) and Clegg (often used for compaction control) comprise rapid undamped impact tests, the SSG (not specified in the UK) and NVM (a research prototype) comprise small devices that measure the response to low energy impulses applied over a range of frequencies-but only impart very small strains to the soil under test. The Loadman and GDP comprise damped impacts of a falling mass onto a bearing plate, (the novelty of the Loadman stemming from its enclosed tube apparatus), and are in many ways mechanically similar to the LWD except that both interpret the impact using an accelerometer rather than directly from a load cell, and in general the interpreted deflection has been observed to be less reliable (Fleming et al, 2002). The TFT was a research prototype developed in 1992, and similar to the current LWD in all ways except it had a relatively high mass bearing plate. The TFT was used in research on live sites in the UK until around the year 2000, whereupon the LWD became commercially available and was the adopted portable dynamic plate test in the UK although it was not formally specified in detail in UK guidance until recently (Highways Agency, 2006). Whilst all the portable devices have their advantages and disadvantages the current LWD (manufactured by Grontmij / Carlbro and Dynatest) has emerged as the most acceptable tool for routine use in the UK whilst retaining some flexibility in test protocol, such as variable plate size, load magnitude, and data collection, with the added and important factor that it most closely resembles the loading rate and area of a (single) moving wheel (Fleming and Rogers, 1995), and functions very similarly to the FWD and uses the same transducer technology.

One particularly important aspect when considering the insitu measurements made is the interpretation of the deflection under load. In general the device software integrates the geophone (velocity transducer) signal to determine the maximum (or peak) deflection value. This has two important ramifications, the first being that under test the peak deflection may not occur at the same instant as the peak load due to dynamic effects, often observed more prominently on lower stiffness materials. The second facet is that the maximum deflection may include an element of permanent/plastic deflection in addition to recoverable/elastic deflection dependent upon the 'strength' of the materials under test, and the efficacy of the contact between the geophone foot and the material under test. Thus, it can be argued that that the term 'elastic' stiffness (E) is not necessarily what the device measures, and in the UK the term stiffness modulus is increasingly used to describe the LWD measured value. The direct use of the measured value of 'stiffness modulus' as 'elastic' input values into design packages that utilize linear elastic algorithms therefore needs careful consideration.

The LWD is shown in Figure 1. The test variables include drop weight, drop height, load contact area, rate of loading and the number of geophones (up to two extra geophones can be connected to allow a limited deflection bowl to be measured). The stiffness modulus (E) from the LWD is calculated using equation 1 given below.

$$
\mathrm{E}=\frac{\mathrm{A} \cdot \mathrm{P} \cdot \mathrm{r} \cdot\left(1-\mathrm{v}^{2}\right)}{\mathrm{d}_{0}} \quad(\mathrm{MPa})
$$

Where:

$\mathrm{E}=$ stiffness modulus $(\mathrm{MPa})$

$\mathrm{A}=$ plate rigidity factor, default $=2$ for a flexible plate, $\pi / 2$ for a rigid plate.

$\mathrm{P}=$ maximum contact pressure $(\mathrm{kPa})$ - controlled by the operator and recorded/displayed

$\mathrm{r}=$ plate radius - can be controlled, 50,75 and $150 \mathrm{~mm}$ options, UK has adopted $150 \mathrm{~mm}$.

$v=$ Poisson's ratio (usually set in the range 0.3-0.45 depending on test material type)

$\mathrm{d}_{0}=$ central geophone peak deflection $(\mathrm{mm})$ - recorded and presented on the readout unit 
The standard equation course assumes a homogeneous linear elastic half space. The depth of significant stressing during a dynamic plate test has been the subject of much speculation during several works (Chaddock and Brown 1995, Fleming et al 2000 \& 2007, Frost 2000 and Hoffman et al 2004, and Mooney and Miller 2008,) and it would appear that in many cases the depth, expressed as a function of the plate diameter, has been quoted as 1-1.5 diameters. Static elastic theory suggests 1.5 diameters. However, it is interesting to note that there is a clear argument to suggest that for layered road foundations the depth of significant stressing is likely to be affected by the stiffness modulus ration of adjacent layers, especially if the upper layer is less than one plate diameter in thickness. In part this is also a function of the rate of loading which is device specific related to the performance of the buffers used to damp the load pulse. In the UK sub-base is usually between $150 \mathrm{~m}$ and $225 \mathrm{~mm}$ thick. The effect of layers has been explained as a factor in assessing the correlation between the full-scale FWD and the smaller portable devices, especially where the load rate of the FWD is slightly longer. One of the difficulties in comparing between devices is the stress dependency (i.e. nonlinear stiffness) of many road foundation materials. The recent work of Mooney and Miller (2008) is an interesting and useful addition to the ongoing scientific debate in that the experimental field work on instrumented sections of granular foundation clearly showed the nonlinear stiffness modulus with depth was required to match predicted to measured absolute values and that equation 1 is a gross simplification of reality.

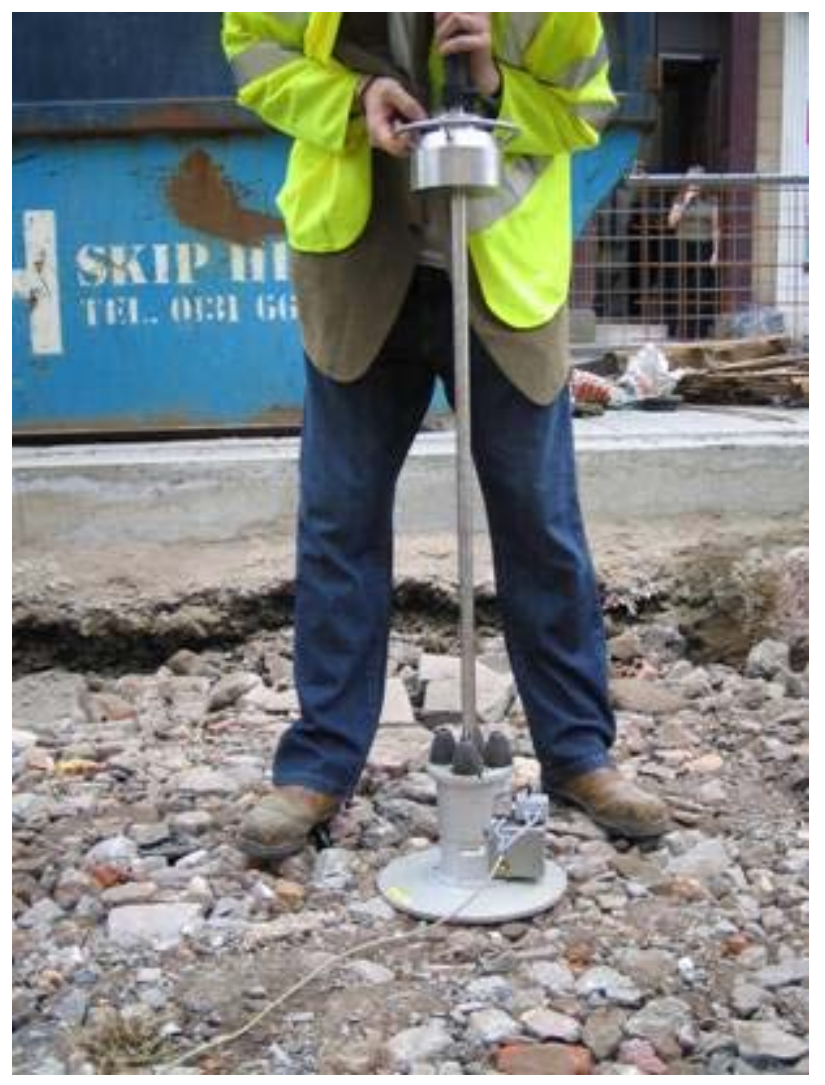

Figure 1. Lightweight Deflectometer - in use on compacted recycled crushed demolition rubble. Note the $300 \mathrm{~mm}$ diameter plate, the falling mass ready for release from a high drop height, and the four rubber buffers which damp the impact and control the load pulse duration. This model is shown with a hardwire transmitting the load cell and geophone measurements.

\subsection{Factors influencing LWD test results}

Controlled laboratory research has considered the potential influence of the many test variables described above to assess the repeatability and reliability of the devices. Over a series of smaller projects, the following variables have been investigated, including buffer temperature, plate di- 
ameter, drop height, drop weight, geophone/loading plate attachment (fixed/loose), use of extra geophones (back analysis), plate-surface contact and depth of significant stressing. The buffer temperature effects and plate-surface contact effects are described in detail below.

The influence of temperature on the LWD buffers and hence loading characteristics was evaluated and it was found that regardless of buffer temperature the measured stiffness remained effectively constant, the only readily observable change was a slight reported lengthening of the load pulse, which was seen to increase with buffer temperature from 18 to 20 milliseconds. This would be expected as the buffers soften slightly when heated.

An investigation was made (Fleming et al, 2007) into the influence of the efficiency of the plate-surface contact, aimed to evaluate if a 'bad' drop could be recognized in the device force and deflection versus time signal (shown on the readout unit). It was clearly demonstrated that an improvement in the regularity of the shape of the deflection trace was observed with improved bearing plate contact. In addition, during the test there was observed to be some bounce and/or horizontal movement of the apparatus, and some vibration back through the device again suggesting poor uniformity of contact. However, the judgment of poor contact is generally subjective, and the on-site assessment of impact quality is potentially difficult. In the laboratory results for one typical test the reported stiffness was $75 \mathrm{MPa}$ for the 'poor' contact and $145 \mathrm{MPa}$ for the 'good' contact. On site such variability in stiffness is common. It was shown that there is merit in examining in more detail the data signal generated at the time of test, and possibly the development of a routine within the software to identify poor quality impact data. Previous work (Nunn et al, 1997) identified site measurements were of poorer repeatability where the aggregate had become segregated at the surface, in particular where there was a lack of fines.

It is also of interest that the geophone and protruding foot are 'spring loaded' to ensure constant contact with the surface. On weaker materials this has been observed to cause local punching failure and affect the magnitude of peak deflection interpreted. It is clear that good site testing protocols using trained and experienced operators is vital, as discussed further in Section 3.

\section{CASE STUDIES AND CORRELATIONS}

\subsection{Case study 1 - in service foundations assessments}

The LWD has been used successfully to assess existing foundations beneath worn sections of highway proposed for reconstruction. One recent scheme comprised a minor road reconstruction where upon the confined foundation stiffness was measured by the LWD in the range 150$245 \mathrm{Mpa}$ with the $300 \mathrm{~mm}$ plate. The variation was attributed to variations in foundation thickness between $300-400 \mathrm{~mm}$, evidenced in the trial pit excavations also carried out but at limited locations. However, the confined stiffness values were considered sufficient to increase confidence in an overlay design. On a second recent scheme the LWD foundation stiffness through core holes was determined as relatively low with an average of $72 \mathrm{MPa}$. This was used as a primary factor in deciding to excavate the road surfacing and compact the foundation prior to reconstruction of the bound road surface. Soft spots were identified, removed and replaced, based on frequent LWD testing during the reconstruction phase.

Conventionally Dynamic Cone Penetrometer (DCP) tests are performed through the base of core holes to evaluate foundations by measuring the change in resistance to penetration with depth, (equated to CBR with depth for convenience). This enables the engineer to better understand the current condition of the existing foundation. However, the possibility of direct stiffness measurement on the foundation, through core holes, with the LWD further supports back analyzed foundation stiffness values derived from a structural Falling Weight Deflectometer survey. DCP testing also has a significant risk in locations densely populated with services, making an alternative means of testing more attractive. Ideally the $300 \mathrm{~mm}$ diameter LWD bearing plate is utilized, through a $450 \mathrm{~mm}$ diameter core hole. The LWD can be used within a $200 \mathrm{~mm}$ diameter core hole if the $100 \mathrm{~mm}$ LWD bearing plate is used, though it has been observed that this smaller diameter provides poor stability during testing and is more affected by large particles. The experience so far is that good quality data can be obtained with the $300 \mathrm{~mm}$ diameter plate through (air cooled) core holes. 


\subsection{Evaluation of existing fill}

The LWD was used successfully on a railway viaduct, to evaluate the variability of the existing fill once the ballast had been removed, prior to reopening as a light rail corridor. The LWD showed a good correlation with locations where the fill was thinner over concrete foundations, (proved by subsequent trial pitting). The mean stiffness value along the route of 190MPa suggested in general a relatively compact engineered fill - though no previous construction records existed. The fill was left in place and formed a suitable substrate to the new trackbed construction.

On a similar scheme the LWD was successfully used to measure the stiffness modulus of existing fill materials at an old factory area that varied in composition from predominantly gravelly clay through to areas of recycled crushed concrete. Part of the site was to be used to form a new site access road to a series of new warehouses. The stiffness identified many soft spots, predominantly in the clay fills, where the water content was above the plastic limit. In the areas of crushed concrete high stiffness values were observed, exceeding 250MPa in general. Much of the better performing material was left insitu and soft spots excavated and replaced with compacted good quality stone.

\subsection{Site Quality control}

The LWD is growing in acceptance as a material and workmanship quality control test on a number of minor road schemes - using the UK target values for lower class foundations. In one recent example the LWD was used to provide assurance of the foundation sub-base construction for a school access and service road that was designed to accommodate some heavy vehicles. The target stiffness of 80MPa was used (Highways Agency, 2006) for 24hrs after construction, prior to laying the bituminous surfacing. Tests were carried out at $10 \mathrm{~m}$ centers in both wheel paths, and of the approximately 100 tests carried out a limited number fell below the target and such areas were remedied by further compaction, and re-tested.

\subsection{Slow curing materials}

The issue of compliance testing on slow curing bound materials in relation to the timing of testing and permission for construction traffic to be allowed access is currently an issue in the new UK guidance. However the LWD has proved useful in monitoring the development of stiffness with time on such materials. As part of a research project for WRAP (Waste and Resources Action Programme - a UK organization aimed at improving sustainability in construction) the LWD was used to monitor the stiffness modulus and stiffness gain with time of a range of hydraulically bound service trench backfill materials. In one case the aim was to reuse the trench arisings, (an as dug gravelly clay), by reworking it with a proprietary binder to improve the properties, and then replacing and compacting it. The data showed the initial stiffness of the reworked material was slightly above the target for granular materials (80MPa) and after 7 days had reached in excess of $200 \mathrm{MPa}$ which was considered wholly acceptable, showing the mix to be fit for purpose (and providing a basis for mix efficiency and binder content).

\subsection{Motorway widening schemes}

The UK is currently constructing many sections of motorway widening to increase capacity on the national network. The LWD was used recently on one such scheme, (a major junction widening scheme using the latest performance related design and specification (Highways Agency, 2006). In this case the contractor had proposed an interesting variation in foundation in comparison to traditional designs, showing the flexibility of the new UK guidance. A traditional Type 1 material (a well graded crushed rock) was to be overlaid with an asphalt layer to form a high stiffness (Class 3) foundation. The LWD was used in parallel with the full size FWD. In general both suggested the sub-base was well constructed and satisfied the design target value of $80 \mathrm{MPa}$, except in two locations that were remediated. The average correlation between the LWD and FWD was close to one, although the point to point correlation showed relatively low repeatability in this case. 


\subsection{Correlations \& Site variability}

In many instances it is considered that the use of the LWD as a 'relative' measure of stiffness modulus insitu is appropriate - e.g. in the case of looking for variations in stiffness and soft spots for subsequent investigation or remediation. However, in the UK the philosophy adopted for motorway and trunk road schemes is one of 'absolute' stiffness values compared to site target values during (re)construction schemes. In this latter case there is a need to provide assurance that an LWD measured stiffness is credible, and this has been assessed on the basis of correlations to the full size FWD derived stiffness (at the same contact stress). The determination of such correlations on live construction sites has been the focus of much of the applied research work in the UK during the development of the relatively new UK road foundation design and specification (Highways Agency, 2006). The experience in the UK is generally that the LWD does, in general, record similar stiffness modulus values to the FWD where the FWD applies the same contact pressure and a similar loading time. The FWD does apply an increased static preload however, due to its greater static mass.

Fleming et al (2007) recently summarized the range of correlation coefficients as 0.8 to 1.4 for LWD:FWD. Other work such as by Nazzal et al, (2006) and Hejlesen and Bultzer (2008) concluded that the ratio of LWD to FWD stiffness was close to unity. The latter work included changing the buffers on the FWD to achieve a similar load pulse duration, which improved the correlation.

In addition to the correlation between devices, it is of interest to observe the typical variability of stiffness with position along a section of notionally the same construction (i.e. same materials, layer thickness and water content). In the UK data has been analyzed in detail and a general pattern has emerged, which is considered useful for selecting the appropriate frequency of testing and also the setting of target values for quality assurance and quality control on site. In general, the variability in any one trial section can be usefully reported as the Coefficient of Variance $(\mathrm{CoV})$, which is the ratio between the standard deviation and the mean for a test section. The reported range of CoV observed was $25-60 \%$ for FWD and LWD on predominantly fine grained subgrades, perhaps due to variation in water content. For granular capping (subgrade improvement) layers the $\mathrm{CoV}$ range observed was 10-40\% (and higher values when wet). For sub-base materials (highly specified well graded crushed rock) the CoV observed was typically less than $15 \%$ (again observed to be higher on very wet sites). In a presentation at an LWD/Intelligent Compaction user meeting in the fall of 2007 in Minnesota, it was very encouraging to note that the values of $\mathrm{CoV}$ reported from a wholly independent study were almost identical for similar material types (White, 2007).

\subsection{Industry opinions(UK)}

Loughborough University have held two one day seminars on the use of LWDs in practice, in 2007 and 2008. These were well attended and it was clear from the numbers attending that the interest in LWDs is increasing in the UK. Several useful datasets of information and opinions were put forward in the formal presentations, together with useful overview of industry trends and opinion from the discussion sessions. Where practicable the salient points have helped inform the best practice guide described in Section 3. A brief summary of the main points from each seminar are presented in the following paragraphs.

From seminar 1 (in 2007) it was clear that LWD manufacture and specification were still developing, in response to industry feedback. This was primarily to provide robust wireless data transmission and user friendly visual display and data analysis tool for site use. The Dynatest LWD was presented as an alternative to the more widely known Carlbro (now Grontmij) model though there is little to differentiate them. The presentations and discussion identified some concerns over the widespread use of LWDs in quality control for major schemes, in particular: on stiffer stabilized foundations where there was concern over inadequate dynamic energy of the LWD to produce a meaningful deflection magnitude. No industry standard or a site test protocol had, at this time, been agreed or published, and there was a long discussion over the number of drops and measurements per test location that was most appropriate, the frequency of tests, data quality issues, and timing of the testing, especially in relation to poor weather and its effects. Experience suggested large variations in stiffness through wetting and drying of many 
foundation materials though it was agreed that just prior to laying the next layer was an appropriate time to test for compliance. Concerns were also expressed over how to objectively assess the quality of a single test and this was discussed at length with regard to experienced operators getting a 'feel' for the test efficacy - though it was pointed out that no formal training schemes or certifications were yet available; concerns were also expressed over repeatability and reproducibility between devices - and no data was yet available to confirm the 'uncertainty' of the measurements made by different devices.

Seminar 2 (in 2008) was a stimulating and useful update of how the LWD had been quite widely used in recent practice and demonstrated the increasing confidence in its use in a commercial environment and that it was generally accepted by Clients for materials assessment and design/construction assurance. A series of presentations descried how the LWD was used as a versatile and simpler/cheaper alternative to the full size FWD. Many of the issues raised during the first seminar a year earlier had, it seemed, been addressed through experience and a natural evolution of practice. A draft best practice guide was presented by a manufacturer, discussed further in Section 3, including a proprietary data quality algorithm that could interrogate the test output signal for indicators of 'problems' in the deflections recorded. A 'hands on' session was also included for those new to LWDs to experience undertaking tests and analysis on a variety of materials compacted into boxes. The closing discussion set the agenda for the UK to produce an important 'best practice' document and training procedure for all operators to gain a recognized consistent standard, for achieving the protocol in practice. Currently the best practice guide and training seminar are being sponsored in the UK's by Britpave (the UKs concrete paving association), which includes members from all aspects of commercial highways work. It is looking to gain acceptance from the UK Highways Agency who are the client for all major road network in England.

\section{BEST PRACTICE GUIDE}

\subsection{Aim}

The aim of the proposed 'best practice' guide in the UK is to ensure that there are: competent operators; well maintained and calibrated equipment; regular consistency checks; industry standard training; clear effective site procedures; and compatibility of data output and reporting.

\subsection{Draft Testing Protocol}

Before the LWD is used its calibration status and its consistency should be checked to ensure reliable accurate data will be measured on site. Appropriate site records should be taken to detail factors such as weather, construction detail, notable visible defects and test location reference. The device's mechanical set-up including plate diameter and number of geophones should be checked and corroborated on the read-out unit to ensure the settings are correct.

To ensure the test location selected is representative of the local area (i.e. for evenness, gradation etc) seating drops at the target applied stress are performed (it is proposed to reduce this to one seating drop on bound material). The target maximum contact stress is in the range of 100 to $200 \mathrm{KPa}$, and should result in maximum deflection of between $40-1800 \mu \mathrm{m}$. The drop height can be adjusted during seating drops to achieve the target contact stress. In the new UK performance specification the target stress is currently set at $100 \mathrm{kPa}$ for granular materials and $200 \mathrm{kPa}$ for bound materials.

(Note: to achieve $200 \mathrm{kPa}$ contact stress with a $300 \mathrm{~mm}$ diameter plate requires extra falling weight masses to be added from the standard $10 \mathrm{~kg}$ to either $15 \mathrm{or} 20 \mathrm{~kg}$. An alternative is to reduce the plate diameter to $200 \mathrm{~mm}$, then the $10 \mathrm{~kg}$ falling mass is sufficient.)

To measure the stiffness modulus, after seating further drops are carried out at the required target stress comprising three drops on unbound materials and one drop on bound materials. The consistency of the results from the three drops should be high and within $10 \%$, or for the bound materials the recorded drop should be close to the seating drop. The quality of impact signal data should be checked to ensure smooth load and deflection pulses. This can be done sufficiently on the screen of the readout unit. Repeat tests should be performed were inconsistent or poor quality data are given, or the absolute values fail the site compliance targets set in the design, 
but all the data must be reported. If the aim is also to assess the stress sensitivity of the materials (useful in design and back analysis procedures), then it is recommended that for unbound materials and cohesive materials the three recorded drops are carried out at increasing contact stress (e.g. $40,70,100 \mathrm{kPa}$ ) and several are done per characteristic construction/material and/or per day. The determination of approximate heights to provide these contact stresses is usually assessed on site at the start of the day.

\subsection{Test quality assessment}

In the absence of any widely available algorithm software to interrogate the test output signals, it has been deemed sufficient to utilize simple diagrammatic examples of good and poor impacts, as shown below in Figures 2 to 4.

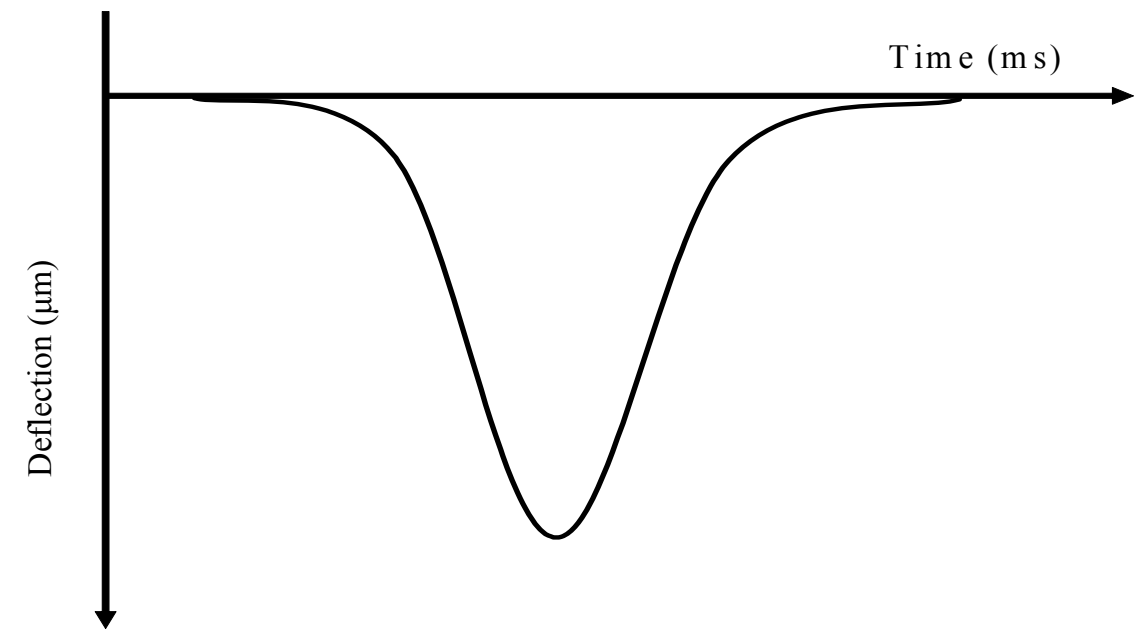

Figure 2. High quality test with deflection - time pulse returning to zero

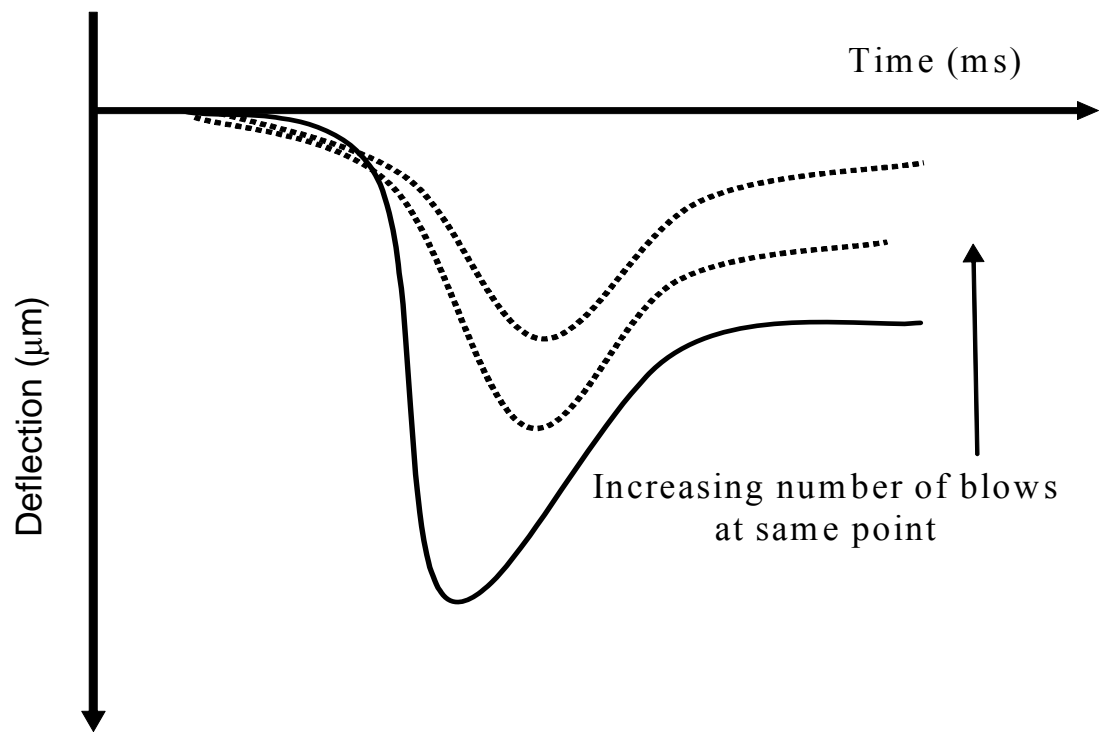

Figure 3. Effect of compaction under testing showing reduced deflection with number of blows and a 'permanent' element of the deflection - time pulse

The use of a material to improve the contact between the bearing plate and the soil surface has also been the subject of some research and discussion. However, to date it has not been formalized into a clear and objective procedure. Fleming et al (2007) reported varying success from smoothing a single sized sand over a coarse or rough surface to improve the contact efficacy. 
This changed the measured stiffness modulus by up to $100 \%$ from the original poor data, and in general a small amount of sand improved contact, though excess sand could reduced the stiffness modulus measured.

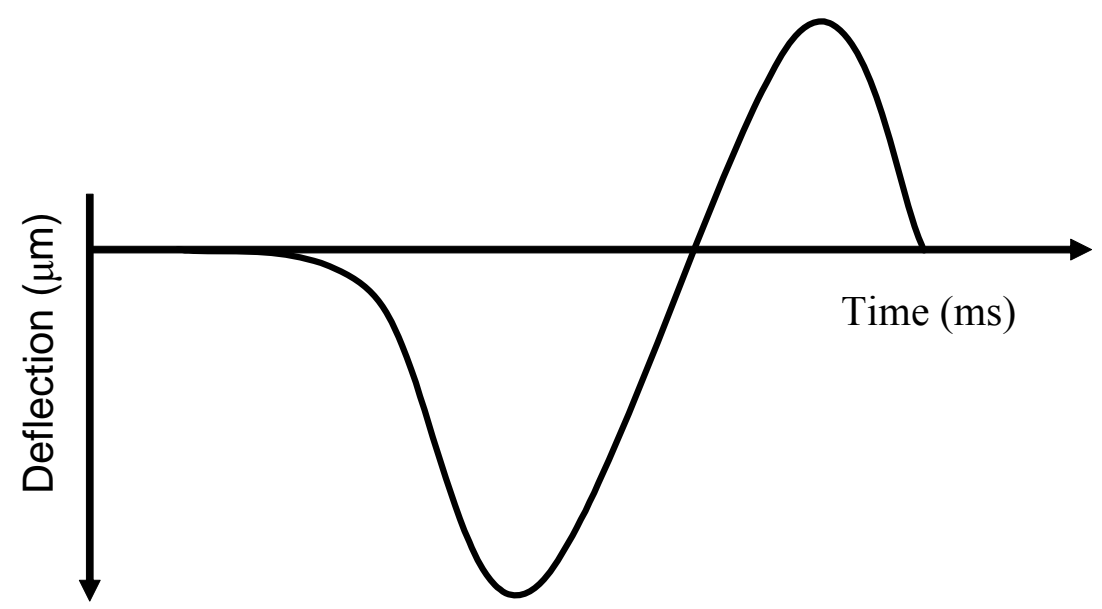

Figure 4. This response may be due to hard material causing the plate to lift off the ground or the presence of excess water, characterized by the high 'rebound' of the deflection to a positive (upward) value in contrast with Figure 2.

The detail of the best practice guide is yet to be finalized in the UK, but may include requirements for calibration certificates and also internal equipment checks to be carried out on known surfaces (e.g. a concrete floor) to check the device is working prior to transporting it to site.

\section{CONCLUSIONS}

The LWD is proving to be a versatile and portable stiffness modulus measurement tool. It appears to be increasingly used on a variety of materials/constructions, both on major schemes and minor road constructions in the UK, primarily during construction but also in investigations prior to reconstruction. It is now specified in recently published UK road foundation design and specification guidance.

The LWD is increasingly being used as a FWD substitute, and has the advantage of portability and ease of use, in addition to lower cost.

The correlation of the LWD to FWD stiffness is often reported as approximately 1, but appears to be variable, and perhaps site dependent.

Recent work has added to the research findings that the depth of significant stressing is around 1 plate diameter.

Several factors affecting LWD data quality and the development of 'best practice' guidance have been presented and discussed. There is some concern over the influence of plate contact efficacy, though some qualitative methods of evaluating the test integrity by the signal shape are emerging. Future workshops and reviews of practice are expected to evolve this guidance further.

The UK is slowly implementing the best practice, concurrent with a new training programme to ensure all site operators are practicing consistent methods for measurement and reporting. 


\section{ACKNOWLEDGEMENTS}

The authors would like to acknowledge the UK Highways Agency, and the Centre for Innovative Construction Engineering at Loughborough University for past collaborations and funding various work packages summarized herein. The opinions expressed are solely those of the authors.

\section{REFERENCES}

Chaddock B. Brown AJ. 1995. Road Foundation Assessment. Proc. of the 4th Int. Symp. Unbound Aggregates in Roads (UNBAR4), Nottingham University, 1995, pp 200-208 (check).

Fleming P R, Frost M W and Rogers C D F, A Comparison of Devices for Measuring Stiffness Insitu. In Unbound Aggregates in Road Construction, editor Andrew R Dawson, Balkema, 2000, pp 193-200.

Fleming P. R., Dixon N., Lambert J, Young C. Monitoring the Performance of Hockey Pitches During Construction, The Engineering of Sport 4, Kyoto, Japan, 2002, pp. 545-552, ed. S Ujihashi and S Haake, Blackwell.

Fleming P. R., Lambert J. P., Frost M. W., Rogers C. D. F., In-situ Assessment of Stiffness Modulus for Highway Foundations During Construction. Presented at the 9th International Conference on Asphalt Pavements, Copenhagen, Denmark, August, 2002, pp12, CD-ROM.

Fleming, P.R., and Rogers, C.D.F. Assessment of Pavement Foundations During Construction. In Transport, Proceedings of the Institution of Civil Engineers, Vol. 111 (2), 1995, pp 105-115.

Fleming P. R., Frost M. W., Lambert J. P., "A Review of the Lightweight Deflectometer (LWD) for Routine Insitu Assessment of Pavement Material Stiffness", Transportation Research Record 2004, Soil Mechanics, 2007 pp. 80-87. ISSN 0361-1981

Frost, M. W. (2000): The Performance of Pavement Foundations during Construction. Ph.D. Thesis. Loughborough University.

Hejlesen C., Baltzer S. 2008. New Danish Test Method for the Lightweight Deflectometer (LWD). In Advances in Transportation Getoechnics, eds. Ellis, Yu, McDowell \& Thom, Taylor and Francis, pp $157-160$.

Highways Agency, Design Guidance for Road Pavement Foundations (Draft HD 25), Interim Advice Note 73, Highways Agency, London, February 2006.

Hoffman, O. Guzina B.B. Drescher A. 2004. Stiffness Estimates Using Portable Deflectometers. Transportation Research Record 186, 59-66.

Mooney, M.A. and Miller, P.K. 2008. Analysis of Light Falling Weight Deflectometer Test based on In-Situ Stress and Strain Response. J. Geotech. \& Geoenv. Engineering, ASCE, to appear 134(10).

Nazzal, M. Abu-Farsakh, M., Alshibli, K. and Mohammed, L., Evaluating the Potential use of a Portable LFWD for Characterising Pavement Layers and Subgrades. Geotechncial Engineering for Transportation Projects: Proceedings of Geo-Trans 2004, Los Angeles, US, 2004.

Nunn, M.E., Brown, A., Weston, D., and Nicholls, J.C.. Design of Long Life Flexible Pavements for Heavy Traffic, TRL report 250, 1997, TRL Limited, London, ISSN 0968-4107.

Rogers, C.D.F., Brown, A.J. and Fleming, P.R.; Elastic Stiffness Measurement of Pavement Foundation Layers, Proc. of the 4th Int. Symp. Unbound Aggregates in Roads (UNBAR4), Nottingham University, 1995, pp 271-280.

White D. 2007. Intelligent Copmaction and Field Assessment of Stiffness, presentation to the MnDOT LWD/Intelligent Compaction workshop, $17^{\text {th }}$ November 2007, Detroit Lakes Minnesota USA. 